\title{
Persistent subretinal fluid due to central serous chorioretinopathy after retinal detachment surgery
}

This article was published in the following Dove Press journal:

Clinical Ophthalmology

10 October 2011

Number of times this article has been viewed

\author{
María Moreno-López \\ Marta Pérez-López \\ Pilar Casas-Llera \\ Elena Jarrín \\ Francisco José Muñoz- \\ Negrete \\ Ophthalmology Unit, Hospital Ramón \\ y Cajal, Madrid, Spain
}

Background: The causes of persistent submacular detachment after successful rhegmatogenous retinal detachment (RRD) surgery remain unknown. Its presence is associated with poor postoperative visual acuity, but due to its spontaneous resolution no additional therapeutic or diagnostic procedure is recommended.

Case report: A case of central serous chorioretinopathy (CSC) that simulated persistent subfoveal fluid after RRD surgery is presented.

Conclusion: To the authors' knowledge, no other case of visual impairment after successful retinal detachment surgery due to CSC has been reported in the PubMed database. In view of this report, CSC should be considered in the differential diagnosis of persistent subretinal fluid after successful retinal detachment surgery.

Keywords: persistent subretinal fluid, retinal detachment surgery, central serous chorioretinopathy, vitrectomy

\section{Introduction}

Persistent submacular fluid after successful rhegmatogenous retinal detachment (RRD) surgery is associated with poor initial visual outcome. ${ }^{1}$ Its spontaneous resolution may take several months and no additional procedure is recommended to accelerate its natural course as it does not seem to influence the final visual acuity. ${ }^{2,3}$ The causes of persistent foveal detachment are unclear; however, its incidence is more often significantly reduced after vitrectomy and gas surgery than after scleral buckle procedure. $^{1,2}$

Central serous chorioretinopathy (CSC) is an idiopathic serous detachment of the macula related to increased adrenergic and steroidal stimulation state and has been reported secondary to different surgical procedures. ${ }^{4-6}$

A case of CSC misdiagnosed as persistent subretinal fluid after successful retinal detachment surgery, with no spontaneous improvement over an 18-month period, is reported here.

\section{Case report}

A 48-year-old phakic man underwent successful pars plana vitrectomy and encircling buckle for a $360^{\circ}$ macula-off RRD in his right eye. Preoperative best corrected visual acuity was light perception. The patient was started postoperatively on prednisolone drops five times per day in a decreasing dosage for the following 5 weeks. At the 5-month visit, best corrected visual acuity was 0.4 in his right eye and persistent submacular fluid was identified on spectral-domain optical coherence tomography
Correspondence: Marta Pérez-López Ctra. de Colmenar Viejo, Km 9100 , Madrid 28034, Spain

Tel +34 649738933

Fax +34963494299

Email marperlo@hotmail.com 
(Figure 1A) with an increased epimacular signal that was believed to be a thickened internal limiting membrane. To relieve tangential macular tractions, which might have accounted for the persistent foveal detachment, the patient underwent a second vitrectomy with internal limiting membrane peeling and long-lasting gas. One month later, an increase in subretinal fluid was noted (Figure 1B). Fundus fluorescein angiography revealed two retinal pigment epithelium leaking points in the juxtafoveolar area, which led to the diagnosis of CSC (Figure 2).

\section{Discussion}

The presence of submacular fluid after successful retinal detachment surgery is associated with poor postoperative visual acuity. No additional therapeutic procedure is recommended due to its spontaneous resolution, which can take up to 18 months and is accompanied by slow visual improvement. Optical coherence tomography is useful in detecting persistent subretinal fluid, which is otherwise difficult to identify on clinical examination. ${ }^{2,7}$
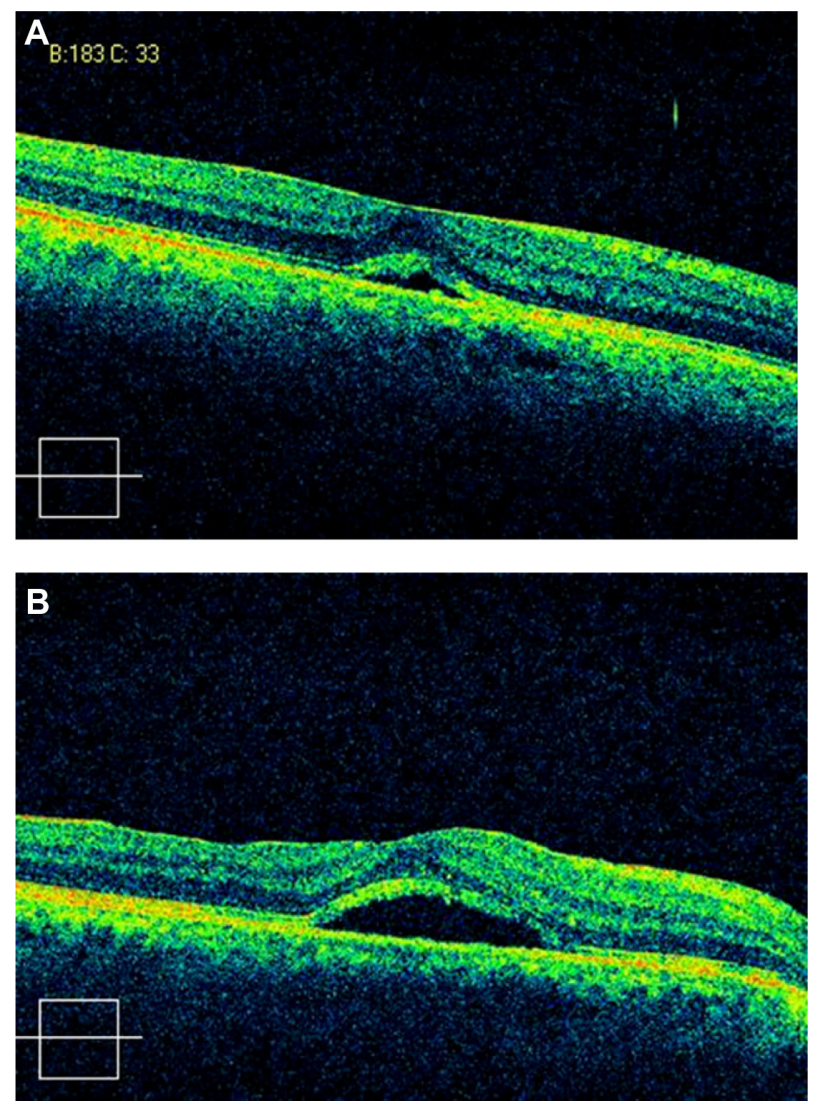

Figure I (A) Spectral-domain optical coherence tomography of the right eye of the patient 5 months after vitrectomy and buckle surgery for retinal detachment showing subretinal fluid in the foveal area with thickened inner limiting membrane; (B) inner limiting membrane subfoveal fluid accumulation persisted 2 weeks after peeling.
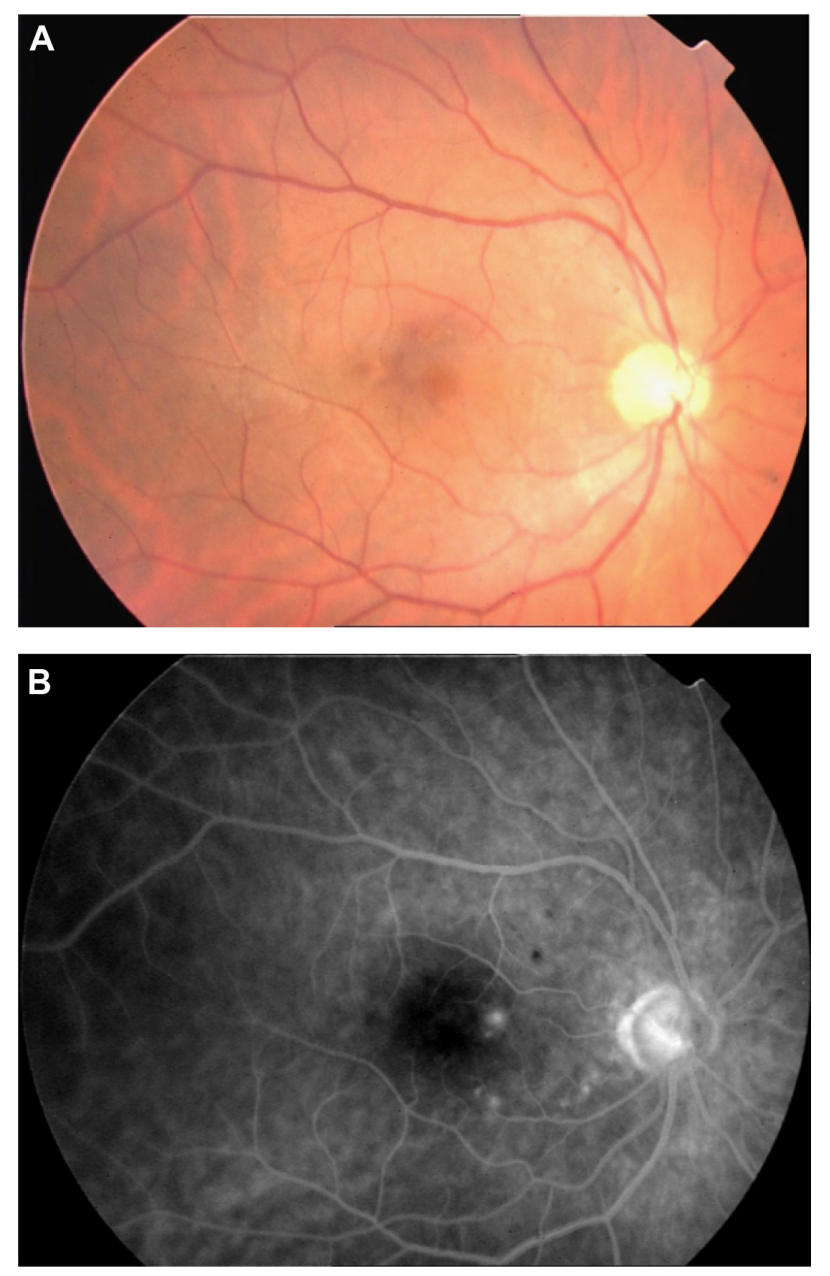

Figure 2 (A) Fundus photograph I month after the second vitrectomy with internal limiting membrane peeling; (B) fundus fluorescein angiogram showing two retinal pigment epithelium leak points in the juxtafoveolar area.

The causes of persistent submacular detachment after successful retinal detachment surgery remain unknown. ${ }^{1-3}$ Its incidence seems to be higher after scleral buckling surgery than after vitrectomy surgery ( $55 \%$ versus $15 \%)$. ${ }^{1,2}$ Complete drainage of subretinal fluid during pars plana vitrectomy plus the displacement of fluid by a large gas bubble have been proposed to explain such differences. ${ }^{1}$ However, no definitive mechanism has been established.

In the patient discussed, CSC simulated persistent subfoveal fluid after RRD surgery. Fundus fluorescein angiography, which is not routinely performed in this setting, revealed retinal pigment epithelium leaking points underlying the detached fovea. It has been proposed that CSC is more likely in patients having type A personality and when its occurrence is preceded by a variety of stressful events in a patient's life. ${ }^{4-6}$ CSC in the patient discussed here could have worsened after the second vitrectomy since subretinal fluid increased after 
internal limiting membrane peeling. Another explanation for the clinical course of this patient could be the persistence of subretinal fluid after RRD repair and the developing of CSC following macular surgery.

\section{Conclusion}

To the authors' knowledge, no other case of visual impairment after successful retinal detachment surgery due to CSC has been reported in the PubMed database. In view of this report, CSC should be considered in the differential diagnosis of persistent subretinal fluid after successful retinal detachment surgery. This disease is associated with increased levels of catecholamines (stress) and glucocorticoids (steroidal medication), both related to ocular surgery for RRD.

\section{Disclosure}

The authors report no conflicts of interest in this work.

\section{References}

1. Benson SE, Schlottmann PG, Bunce C, Xing W, Charteris DG. Optical coherence tomography analysis of the macula after vitrectomy surgery for retinal detachment. Ophthalmology. 2006;113(7):1179-1183.

2. Abouzeid H, Becker K, Holz FG, Wolfensberger TJ. Submacular fluid after encircling buckle surgery for inferior macula-off retinal detachment in young patients. Acta Ophthalmol. 2009;87(1):96-99.

3. Seo JH, Woo SJ, Park KH, Yu YS, Chung H. Influence of persistent submacular fluid on visual outcome after successful scleral buckle surgery for macula-off retinal detachment. Am J Ophthalmol. 2008; 145(5):915-922.

4. Fawzi AA, Cunningham ET Jr. Central serous chorioretinopathy after bone marrow transplantation. Am J Ophthalmol. 2001;131(6):804-805.

5. Lim MC, Chan TK. Central serous chorioretinopathy following LASIK for hyperopia. J Refract Surg. 2008;24(6):651-652.

6. Mondal L, Basu S, Baidya K, Bhaduri G. Central serous chorioretinopathy after dacryocystorhinostomy operation on the same side. Indian J Ophthalmol. 2009;57(1):57-58.

7. Benson SE, Schlottmann PG, Bunce C, Xing W, Charteris DG. Optical coherence tomography analysis of the macula after scleral buckle surgery for retinal detachment. Ophthalmology. 2007;114(1):108-112.
Clinical Ophthalmology

\section{Publish your work in this journal}

Clinical Ophthalmology is an international, peer-reviewed journal covering all subspecialties within ophthalmology. Key topics include: Optometry; Visual science; Pharmacology and drug therapy in eye diseases; Basic Sciences; Primary and Secondary eye care; Patient Safety and Quality of Care Improvements. This journal is indexed on

Submit your manuscript here: http://www.dovepress.com/clinical-ophthalmology-journal

\section{Dovepress}

PubMed Central and CAS, and is the official journal of The Society of Clinical Ophthalmology (SCO). The manuscript management system is completely online and includes a very quick and fair peer-review system, which is all easy to use. Visit http://www.dovepress.com/ testimonials.php to read real quotes from published authors. 